\title{
Design of Coronary Stent: Identification and Analysis of Parameters
}

\author{
D. K. Baroroh", and M. Ridwan
}

\begin{abstract}
In Indonesia, the need for coronary stents is still very high and has the potential to increase every year, but overall in fulfillment is still met by foreign-made or imported stents. This is due to the absence of stent design made in Indonesia. Stent design or design is an important factor that must be considered from a stent because it affects the function of the stent when used in the body of patients who experience narrowing of the arteries. Flexibility in stent design is one of the important factors to get good quality of stents and solution for the problem. Flexibility can be represented by curvature index and von mises. This research will begin by identifying and analyzing the parameters of bending moment and thickness of stent to achieve the highest Curvature Index ( $\mathrm{rad} / \mathrm{mm})$ and Von Mises (MPa) by $2 \mathrm{k}$ factorial design. The analysis parameter response is done using finite element analysis by Abaqus Finite Element Analysis (FEA). The results obtained from this research that bending moment, thickness and interaction have a significant influence on the value of curvature index (CI) and von mises (VM), especially in expanded configuration of stent. The influence of each factor on the value of CI and VM formulated in the form of linear regression model, the following equation are formed $\mathrm{CI}_{\text {prediction }}=0.0766+0.0139 \mathrm{M}-0.0047 \mathrm{~T}+$ $0.0008 \mathrm{MT}$, and $\mathrm{VM}_{\text {prediction }}=49.695+12.584 \mathrm{M}-2.697 \mathrm{~T}-0.389 \mathrm{MT}$. From combination analysis generated the optimum response for $\mathrm{CI}$ and VM occur at bending moment $0.02 \mathrm{Nmm}$ and thickness $60 \mu \mathrm{m}$ with CI value of $0.09434 \mathrm{rad} / \mathrm{mm}$ and $\mathrm{VM}$ value of $65.275 \mathrm{MPa}$.
\end{abstract}

Keywords-Coronary Stent, Flexibility, and Finite Element Analysis.

\section{INTRODUCTION}

$\mathrm{A}$ CCORDING to the world statistics, there are approximately 9.4 million deaths each year caused by cardiovascular disease and $45 \%$ of the causes of the death due to coronary heart disease [1]. Because it does not require surgery, has a lower risk of complication, faster installation and healing times than bypass, and also more effective in preventing restenosis, that superiority of stent installation resulting as many selected alternative [2]. Therefore, since it has been first developed in the 1980s, more than 100 coronary stents marketed and evaluated worldwide [3]. The total requesting number of stents in 3 major Indonesian hospitals by 2012 reach 4000 stents [4], moreover, according to Global coronary stents market approximate to reach USD 6.4 billion by 2024 from

Manuscript received August 31, 2017. This research was supported by Research Directorat of Universitas Gadjah Mada, No. 364 / DIT.LIT / 2017.

D. K. Baroroh is researcher at Department of Mechanical and Industrial Engineering, Universitas Gadjah Mada, Yogyakarta, Indonesia (e-mail: dawi.karomati.b@mail.ugm.ac.id).

M. Ridwan is student at Department of Mechanical and Industrial Engineering, Universitas Gadjah Mada, Yogyakarta, Indonesia.
USD 5.3 billion in 2016, at a CAGR of $2.4 \%$ in the forecast period 2017 to 2024.

In related to the stent design, there were three factors that need to be considered including medical, engineering and manufacturing [5]. Coronary stent variation can be observed from four main aspects, namely the material type, form, fabrication process, and geometry shape [3]. Currently, there is a metal based stent that commercially available in various designs and materials. Improvement of the existing stent and finding alternative materials are very challenging, and these have attracted many researchers around the globe. In medical aspect, materials of stent have to be biocompatible [6], [7] and the stent was no cause restenosis and thrombosis [8]; while cardiologists want to install the stent easier and comfortable [9]. Since the stent has to pass through a complex passage artery before arriving at the blockage location. While for manufacturers, they need ease of manufacturability for a given design and material. Flexibility of the stent is a very important factor [10], because it is needed in the process of transporting the stent to the location of the blockage. The flexibility of the stent can be seen from the given bending moment values derived from the stent link design [11], [12], and also the thickness [13].

The majority of stents in the market is made of non-degradable metal such as stainless steel (316L), cobalt chromium alloy, and titanium alloy nickel [14]. For 6 to 12 months there will be a process of remodeling in the blood vessels that make the arterial tissue to find new equilibrium point due to the installation of a stent [15], [16]. The presence of long-lasting permanent stents in the body can lead to lax stents, fractures, tissue inflammation, restenosis, and thrombosis [11]. Thus, biodegradable materials such as magnesium based alloys, pure iron, iron based alloys, and polymers are a promising alternative solution. Biodegradable metallic materials essentially have better mechanical strength compared to polymers, but polymers have a degradation time that is more suited to the time it takes the arteries to reach a new equilibrium point [15], [17], [18].

PLLA standard stents circulating in the market so far have a thickness above $100 \mu \mathrm{m}$ [19]. However, Biotronics (2017) announced that they managed to make a stent with a thickness of $60 \mu \mathrm{m}$. Therefore, in this research will examine the flexibility of stent made from PLLA with thickness $60 \mu \mathrm{m}-70 \mu \mathrm{m}$. In addition, optimization of flexibility design parameters will be designated by curvature index on stents with thickness of 60 $\mu \mathrm{m}-70 \mu \mathrm{m}$ with a bending moment of $0.01 \mathrm{~N} . \mathrm{mm}-0.02 \mathrm{~N} . \mathrm{mm}$ on stents with expanded configuration. Research analysis used factorial design method, because this method is sufficient 
accurate method to get better or improve quality part, and it gave a smaller error than Taguchi method [20].

\section{MATERIALS AND METHODS}

\section{A. Material}

The material of this research is Poly-L-Lactic Acid (PLLA) stent with balloon-expandable expansion mechanism. The strut contrary stretch design has a strut that is in the opposite direction to the longitudinal axis and has 4 links, with the size as described in the Figure 1 and focus on stents with expanded configuration (Fig. 1 and 2). Mechanical properties for PLLA namely yield strength $\left(\sigma_{\mathrm{y}}\right)$ is $62.5 \mathrm{MPa}$, the ultimate tensile strength $\left(\sigma_{\mathrm{u}}\right)$ is $65 \mathrm{MPa}$, the modulus young $(\mathrm{E})$ is $1.8 \mathrm{GPa}$, the Poisson ratio $(0)$ is 0.35 and the density $(\rho)$ is $1.25 \mathrm{~g} / \mathrm{cm}^{3}[21]$.

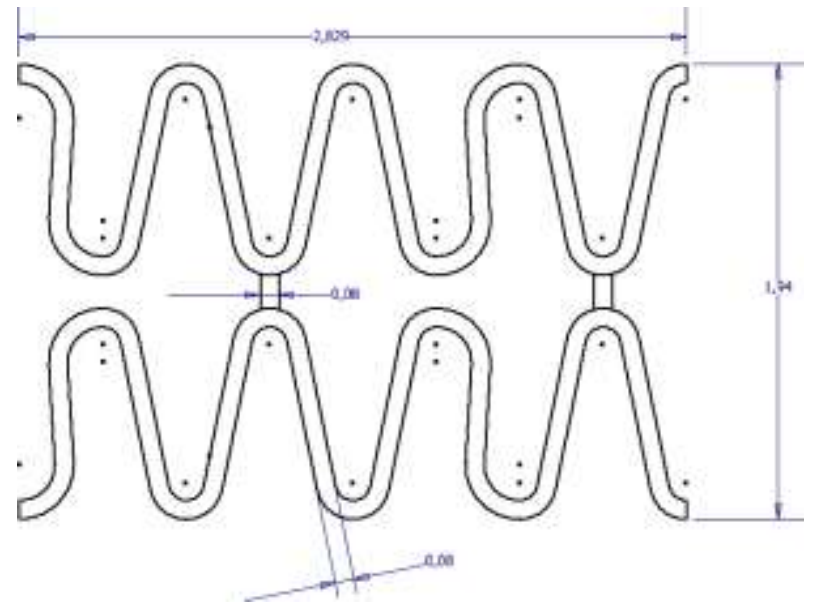

Fig. 1. Expanded of Design Stent 2D

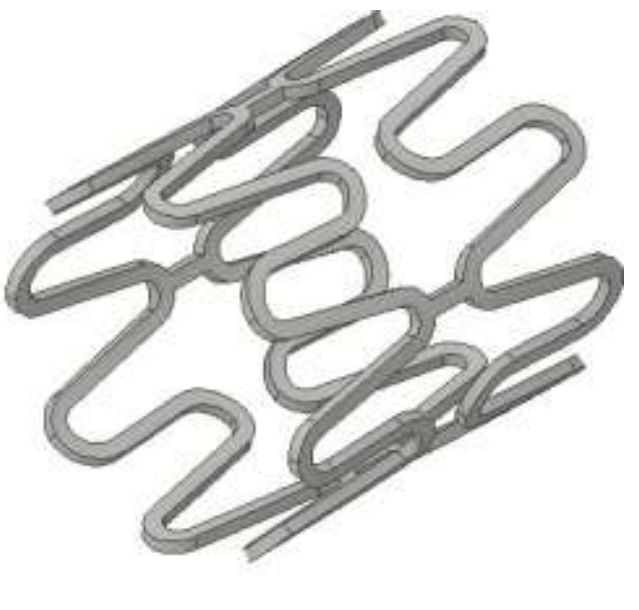

Fig. 2. Expanded of Design Stent 3D

\section{B. Tools}

There are some primary tools for supporting this research such as:

1. Autodesk Inventor Professional 2016 for desigining 2D or $3 \mathrm{D}$ of stent design.
2. Abaqus 6.11 for engineering simulation analysis with function of finite element analysis.

3. Minitab 15 for creating experimental designs, for processing statistical data, for building mathematical model equations and for predicting the optimum value of the model.

\section{Methodology}

This research is done using several stages which are described in Fig. 3.

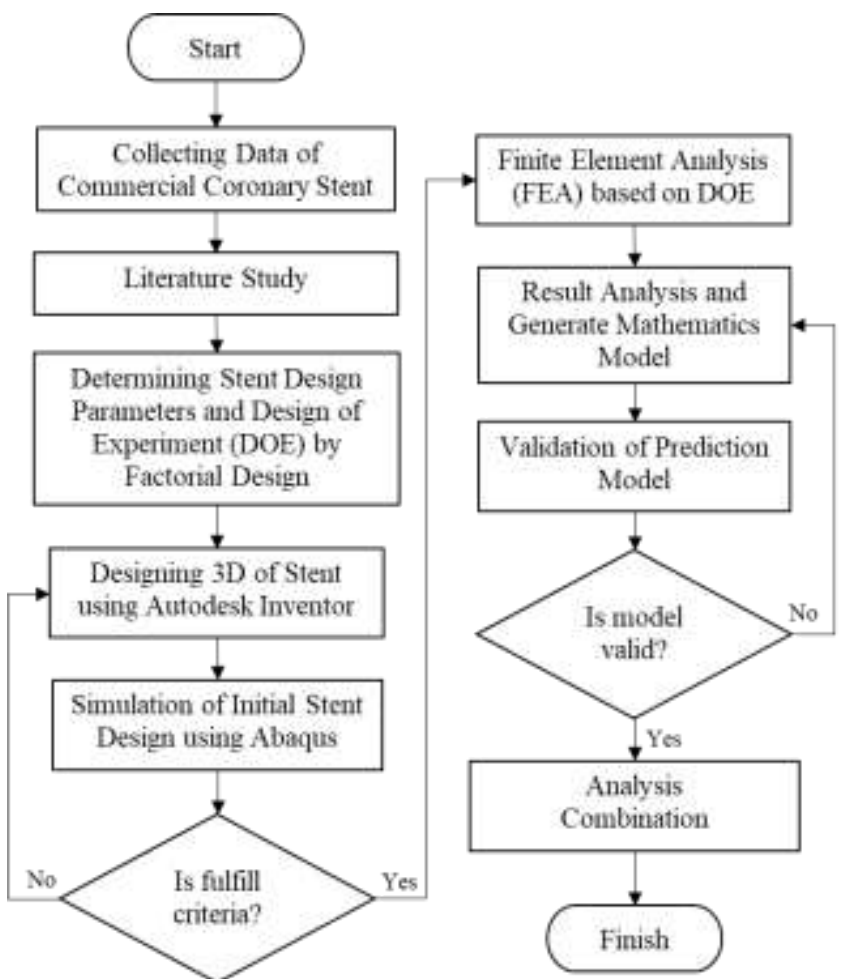

Fig. 3. Research Methodology

This research used 2 parameters with 2 levels and using experimental design, namely $2 \mathrm{k}$ factorial design that as shown in Table I. There are 4 combinations (Table II), and run with 3 replications (total experiment are 12 runs) and is done randomly to minimize bias of data.

TABLE I:

PARAMETER AND LEVEL OF EXPERIMENT

\begin{tabular}{lcc}
\hline \hline \multirow{2}{*}{ Parameter } & \multicolumn{2}{c}{ Level } \\
\cline { 2 - 3 } & $\mathbf{- 1}$ & $\mathbf{+ 1}$ \\
\hline Bending Moment/ M (N.mm) & 0.01 & 0.02 \\
Stent Thickness/ T $(\mu \mathrm{m})$ & 60 & 70 \\
Responses are Curvature Index $(\mathrm{rad} / \mathrm{mm})$ and Von Mises $(\mathrm{MPa})$ \\
\hline \hline
\end{tabular}

Theoretically, flexibility of stent is presented as a curvature index, $\mathrm{X}(\mathrm{rad} / \mathrm{mm})$ which is counted as a ratio of rotation angle to the length of stent. Suppose the length is noted as $\mathrm{L}(\mathrm{mm})$, bending moment is $\mathrm{M}(\mathrm{kg} . \mathrm{m})$ and the rotation angle $\Delta \varnothing(\mathrm{rad})$, thus the curvature index can be determined using (1) [11].

$$
\mathrm{X}=\underline{\Delta \emptyset}
$$

TABLE II:

DESIGN OF EXPERIMENT

\begin{tabular}{lll}
\hline \hline Run & Coded Variable & Actual Variable \\
\hline \hline
\end{tabular}




\begin{tabular}{ccccc}
\hline \hline & $\begin{array}{c}\mathbf{M} \\
(\mathbf{N} . \mathbf{m m})\end{array}$ & $\begin{array}{c}\mathbf{T} \\
(\boldsymbol{\mu} \mathbf{m})\end{array}$ & $\begin{array}{c}\mathbf{M} \\
(\mathbf{N} . \mathbf{m m})\end{array}$ & $\begin{array}{c}\mathbf{T} \\
(\boldsymbol{\mu} \mathbf{m})\end{array}$ \\
\hline 1 & -1 & -1 & 0.01 & 60 \\
2 & -1 & 1 & 0.01 & 70 \\
3 & 1 & -1 & 0.02 & 60 \\
4 & 1 & 1 & 0.02 & 70 \\
\hline \hline
\end{tabular}

After each response is known, then the next is to build mathematical modeling. In describing the effect of the two factors used mathematical models that follow the equation of linear regression models using (2) as below [22]:

$$
\mathrm{Y}=\beta_{0}+\beta_{1} \cdot \mathrm{M}+\beta_{2} \cdot \mathrm{T}+\beta_{12} \cdot \mathrm{MT}
$$

where:

$\mathrm{Y}=$ output/results,

$\beta_{0}=$ average results of the experiment,

$\beta_{1}=$ coefficient of parameter-1 (bending moment),

$\beta_{2}=$ coefficient of parameter-2 (thickness),

$\beta_{12}=$ coefficient of interaction,

$\mathrm{M}$ = optimum level of parameter-1 (bending moment),

$\mathrm{T}=$ optimum level of parameter-2 (thickness),

MT = optimum level of interaction.

\section{RESULTS AND DISCUSSION}

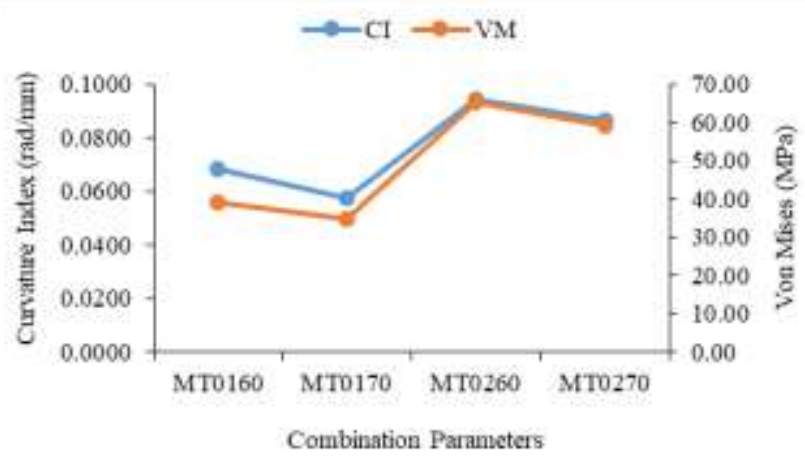

Fig. 4. Comparison Both of the Responses

Based on Fig. 4 is described that combination parameter both of responses is having similar pattern. Futhermore, to know more deeply, so it can be analysis using statistic for each response.

\section{A. Curvature Index (CI)}

In statistic analysis, type of data distribution is very important to know what is the method. If the distribution is normal, so it can be solved by parametric method and vice versa by non-parametric [23]. This research using Shapiro wilk method for normality test, and is obtained that P-value (0.078) > $\alpha(5 \%)$ (as seen in Fig. 5). It is means that Fail to reject Ho or data normally distributed and it can be used parametric method.

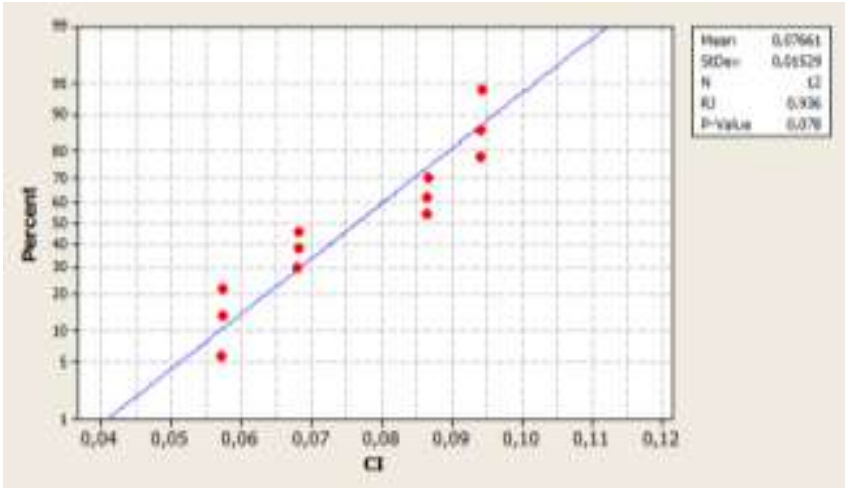

Fig. 5. Normality Test of Response CI

From analysis main effect plot (Fig. 5), it can inferred that bending moment (M) and thickness (T) has different effects to curvature index $(\mathrm{CI})$. Where bending moment give positive effect with increasing level, and vice versa for thickness. Moreover, to get the biggest curvature index is combination between high levels of bending moment and low level of thickness.

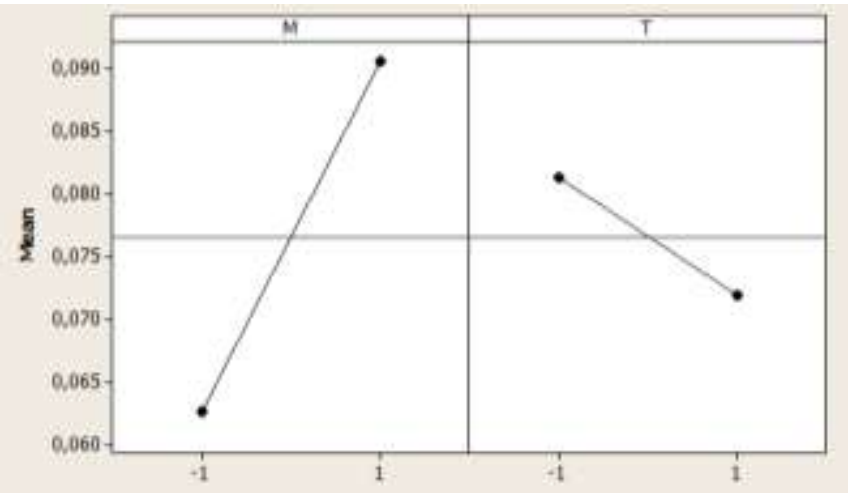

Fig. 6. Main Effect Plot for Response CI

The results of variance analysis test showed that each variable either main effect and interaction have a significant effect on the response of curvature index showed the value of P-value $<(\alpha=5 \%)$ can be seen in Table III. Nevertheless effect of interaction is lower than main effect.

TABLE III:

ANALYSIS OF VARIANCE FOR RESPONSE CI

\begin{tabular}{lccccc}
\hline \hline \multicolumn{1}{c}{ Source } & df & Adj SS & Adj MS & F & P-value \\
\hline Main effect & 2 & 0.00257 & 0.00128 & 153902,50 & 0.0001 \\
Interaction & 1 & 0.00001 & 0.00001 & 902,50 & 0.0001 \\
Residual error & 8 & 0.00000 & 0.00000 & & \\
Pure error & 8 & 0.00000 & 0.00000 & & \\
\hline
\end{tabular}

Furthermore, from the T test can be resulted P-value $<(\alpha=$ $5 \%$ ). It means the parameter of bending moment, thickness and interaction, as a whole has a significant influence on the response CI (Table IV). 
TABLE IV:

T-TEST FOR RESPONSE CI

\begin{tabular}{lccc}
\hline \hline \multicolumn{1}{c}{ Term } & Coefficient & T & P-value \\
\hline Constant & 0.07661 & 2097.08 & 0.0001 \\
$\mathrm{M}$ & 0.01386 & 525.89 & 0.0001 \\
$\mathrm{~T}$ & -0.00466 & -176.77 & 0.0001 \\
$\mathrm{M}^{*} \mathrm{~T}$ & 0.00079 & 30.04 & 0.0001 \\
\hline \hline
\end{tabular}

Results from $\mathrm{T}$ test can be used to represent the linear regression model using (2):

$$
\mathrm{CI}_{\text {prediction }}=0.0766+0.0139 \mathrm{M}-0.0047 \mathrm{~T}+0.0008 \mathrm{MT}
$$

That prediction model has R-square $99.99 \%$, it shows good model for describing variable or parameter.

TABLE V:

\section{COMPARISON RESULT CI ACTUAL VS CI PREDICTION}

\begin{tabular}{cc}
\hline \hline CI Actual (rad/mm) & CI Prediction (rad/mm) \\
\hline 0.0943 & 0.09434 \\
0.0944 & 0.09434 \\
0.0943 & 0.09434 \\
\hline \hline
\end{tabular}

Based on data from Table $\mathrm{V}$ which is generated using (3), validation of model prediction is done by independent t-test, and $\mathrm{P}$-value $(0.85)>5 \%(\alpha)$, it means fail to reject Ho or there is no significant differences between actual experiment and prediction output.

\section{B. Von Mises (VM)}

In response of von mises, it is obtained P-value $(0.062)>\alpha$ (5\%) (as seen in Fig. 7). It means that Fail to reject Ho or data normally distributed and it can be completed by parametric method.

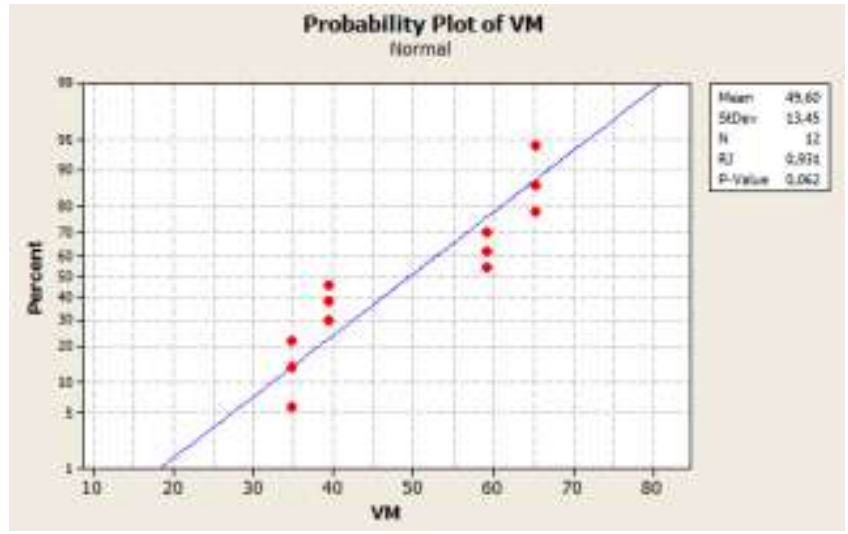

Fig. 7. Normality Test of Response VM

Same with analysis in response of CI, where in analysis main effect plot of response VM (Fig. 8), it can inferred that bending moment give positive effect with increasing level, and vice versa for thickness. Moreover, to get the biggest von mises is combination between high levels of bending moment and low level of thickness.

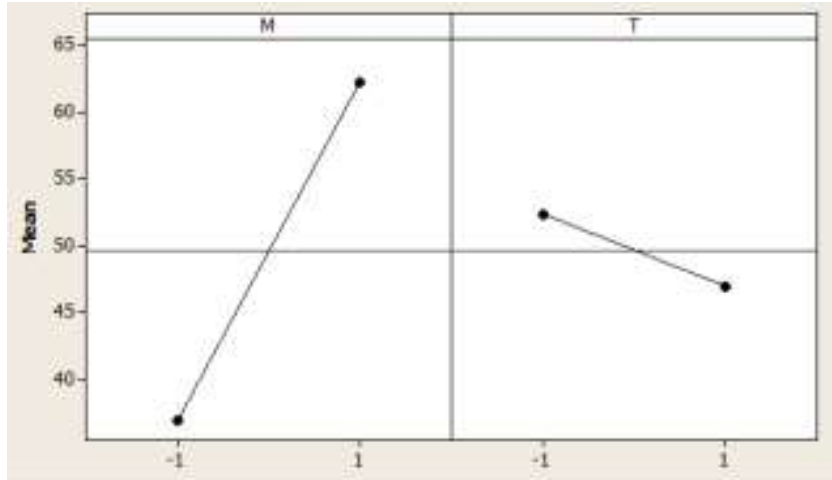

Fig. 8. Main Effect Plot for Response VM

The results of variance analysis test showed that each variable either main effect and the interaction have a significant effect on the response von mises showed the value of P-value < $(\alpha=5 \%)$ can be seen in Table VI.

TABLE VI.

ANALYSIS OF VARIANCE FOR VM

\begin{tabular}{lccccc}
\hline \hline \multicolumn{1}{c}{ Source } & df & Adj SS & Adj MS & F & P-value \\
\hline Main effect & 2 & 1987.73 & 993.866 & $2.98 \mathrm{E}+11$ & 0.0001 \\
Interaction & 1 & 1.81 & 1.811 & $5.43 \mathrm{E}+8$ & 0.0001 \\
Residual error & 8 & 0.00 & 0.000 & & \\
Pure error & 8 & 0.00 & 0.000 & & \\
Total & 11 & & & & \\
\hline \hline
\end{tabular}

Furthermore, from the T test can be resulted $\mathrm{P}$-value $<(\alpha=$ $5 \%$ ). It means the parameter of bending moment, thickness and interaction have significant influence on the response CI (Table VII).

TABLE VII:

T-TEST FOR RESPONSE VM

\begin{tabular}{lccc}
\hline \hline \multicolumn{1}{c}{ Term } & Coefficient & T & P-value \\
\hline Constant & 49.605 & 2976282.5 & 0.0001 \\
$\mathrm{M}$ & 12.584 & 755067.5 & 0.0001 \\
$\mathrm{~T}$ & -2.697 & -161841.5 & 0.0001 \\
$\mathrm{M} * \mathrm{~T}$ & -0.389 & -23310.5 & 0.0001 \\
\hline \hline
\end{tabular}

Results from $\mathrm{T}$ test can be used to represent the linear regression model using (2):

$$
\mathrm{VM}_{\text {prediction }}=49.695+12.584 \mathrm{M}-2.697 \mathrm{~T}-0.389 \mathrm{MT}
$$

That prediction model has R-square $99.99 \%$, it shows good model for describing of variable or parameter.

TABLE VIII:

\begin{tabular}{cc} 
COMPARISON RESULT VM ACTUAL VS VM PREDICTION \\
\hline \hline VM Actual (MPa) & VM Prediction (MPa) \\
\hline 65.275 & 65.275 \\
65.2751 & 65.275 \\
65.275 & 65.275 \\
\hline \hline
\end{tabular}

Validation prediction model is done by independent t-test, and P-value $(0.37)>5 \%(\alpha)$, it means fail to reject Ho or there is no significant differences between actual experiment and prediction output. 


\section{Combination Analysis}

In addition, the combination for each conducted the search of optimum combination was used graphical method by using the intersection graphs plot between curvature index $(\mathrm{CI})$ and von mises (VM) of predictive regression equation for each response to each factor.

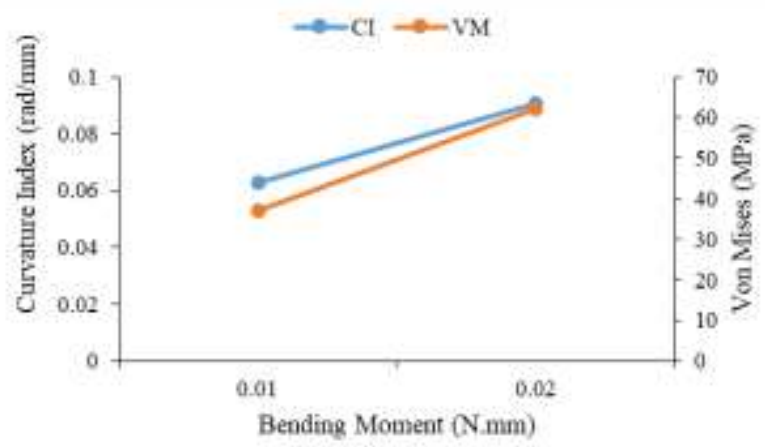

Fig. 9. Analysis of mixtures based on Bending Moment

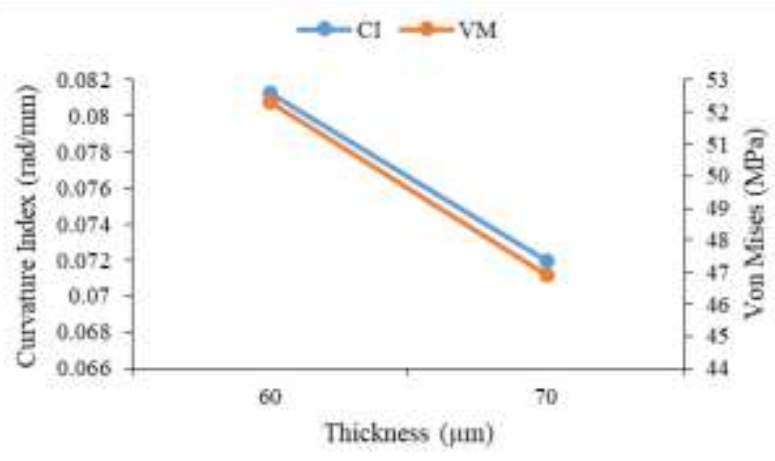

Fig. 10. Analysis of mixtures based on Thickness

Based on Fig. 9 and 10, it can be the result that the optimum combination of considering both response (mixture) are for maximizing curvature index and von mises occur at bending moment $0.02 \mathrm{Nmm}$ and thickness $60 \mu \mathrm{m}$ with $\mathrm{CI}$ value of $0.09434 \mathrm{rad} / \mathrm{mm}$ and VM value of $65.275 \mathrm{MPa}$.

\section{CONCLUSION}

The results obtained from this research that bending moment, thickness and interaction have a significant influence on the value of curvature index (CI) and von mises (VM) in expanded configuration of stent. The influence of each factor on the value of $\mathrm{CI}$ and VM formulated in the form of linear regression model, the following equation is formed $\mathrm{CI}_{\text {prediction }}=$ $0.0766+0.0139 \mathrm{M}-0.0047 \mathrm{~T}+0.0008 \mathrm{MT}$, and $\mathrm{VM}_{\text {prediction }}=$ $49.695+12.584 \mathrm{M}-2.697 \mathrm{~T}-0.389 \mathrm{MT}$. From combination analysis generated the optimum response for $\mathrm{CI}$ and $\mathrm{VM}$ occur at bending moment $0.02 \mathrm{Nmm}$ and thickness $60 \mu \mathrm{m}$ with $\mathrm{CI}$ value of $0.09434 \mathrm{rad} / \mathrm{mm}$ and VM value of $65.275 \mathrm{Mpa}$.

\section{REFERENCES}

[1] World Health Organization, "A global brief on Hypertension-Silent killer, global public health crisis," 2013.

[2] A. D. Michaels and K. Chatterjee, "Cardiology patient pages. Angioplasty versus bypass surgery for coronary artery disease.," Circulation, vol. 106, no. 23, pp. e187-90, 2002.

[3] D. Stoeckel, C. Bonsignore, and S. Duda, "A survey of stent designs," Minim. Invasive Ther. Allied Technol., vol. 11, no. 4, pp. 137-147, 2002.

[4] A. E. Tontowi, P. Ikra, and W. Siswomihardjo, "Mapping of coronary stent demand of several hospitals in Indonesia and its forecasting," in Proc. of 2013 3rd Int. Conf. on Instrumentation, Communications, Information Technol., and Biomedical Engineering: Science and Technol. for Improvement of Health, Safety, and Environ., ICICI-BME 2013, 2013, pp. 436-439.

[5] A. Tontowi, R. Amalia Adani, I. Sekar Setyaningtyas, and N. Taufik, Analysis of User Acceptability Factors for Optimum Design of Coronary Stent. 2014.

[6] G. Mani, M. D. Feldman, D. Patel, and C. M. Agrawal, "Coronary stents: A materials perspective," Biomaterials, vol. 28, no. 9. pp. 1689-1710, 2007.

[7] B. O'Brien and W. Carroll, "The evolution of cardiovascular stent materials and surfaces in response to clinical drivers: A review," Acta Biomaterialia, vol. 5, no. 4. pp. 945-958, 2009.

[8] H. Hara, M. Nakamura, J. C. Palmaz, and R. S. Schwartz, "Role of stent design and coatings on restenosis and thrombosis," Advanced Drug Delivery Reviews, vol. 58, no. 3. pp. 377-386, 2006.

[9] G. Nollert and S. Wich, "Planning a cardiovascular hybrid operating room: The technical point of view," Heart Surgery Forum, vol. 12, no. 3. 2009.

[10] W. Wu, D. Z. Yang, M. Qi, and W. Q. Wang, "An FEA method to study flexibility of expanded coronary stents," J. Mater. Process. Technol., vol. 184, no. 1-3, pp. 447-450, 2007.

[11] L. Petrini, F. Migliavacca, F. Auricchio, and G. Dubini, "Numerical investigation of the intravascular coronary stent flexibility," $J$. Biomech., vol. 37, no. 4, pp. 495-501, 2004.

[12] N. Demanget et al., "Computational comparison of the bending behavior of aortic stent-grafts," J. Mech. Behav. Biomed. Mater., vol. 5, no. 1, pp. 272-282, 2012.

[13] S. Prabhu, C. Feezor, A. Denison, N. Rebelo, and M. Serrar, "Deployment of a Self-expanding Stent in an Artery," ABAQUS Users" Conf., pp. 177-182, 2004.

[14] Q. Wang, G. Fang, Y. Zhao, G. Wang, and T. Cai, "Computational and experimental investigation into mechanical performances of Poly-L-Lactide Acid (PLLA) coronary stents," J. Mech. Behav. Biomed. Mater., vol. 65, pp. 415-427, 2017.

[15] H. Hermawan, D. Dubé, and D. Mantovani, "Developments in metallic biodegradable stents," Acta Biomaterialia, vol. 6, no. 5. pp. 1693-1697, 2010.

[16] S. Ramcharitar and P. W. Serruys, "Biodegradable stents," Minerva Cardioangiologica, vol. 56, no. 2. pp. 205-213, 2008.

[17] S. Garg and P. W. Serruys, "Coronary stents: Looking forward," Journal of the American College of Cardiology, vol. 56, no. 10 SUPPL. 2010.

[18] M. Moravej and D. Mantovani, "Biodegradable metals for cardiovascular stent application: Interests and new opportunities," International Journal of Molecular Sciences, vol. 12, no. 7. pp. 4250-4270, 2011.

[19] H. Y. Ang, H. Bulluck, P. Wong, S. S. Venkatraman, Y. Huang, and N. Foin, "Bioresorbable stents: Current and upcoming bioresorbable technologies," International Journal of Cardiology, vol. 228. pp. 931-939, 2017.

[20] A. E. Tontowi, K. P. Raharjo, R. I. Sihaloho, and D. K. Baroroh, "Comparison of Design Method for Making Composite of (PMMA/HA/Sericin)," Mater. Sci. Forum, vol. 901, pp. 85-90, 2017.

[21] R. G. Pauck and B. D. Reddy, "Computational analysis of the radial mechanical performance of PLLA coronary artery stents," Med. Eng. Phys., vol. 37, no. 1, pp. 7-12, 2015.

[22] D. C. Montgomery, Design and Analysis of Experiments Eighth Edition. 2013.

[23] D. C. Montgomery, Applied Statistics and Probability for Engineers Third Edition, vol. 37, no. 4. 2003. 